\title{
Mengantisipasi Penyalahgunaan Narkoba Pada Remaja GPI Batu Aji Centre
}

\author{
Rita Evimalinda ${ }^{1}$, Ester Lina Situmorang ${ }^{2}$, Asih R. E. Sumiwi ${ }^{3}$, Benteng Martua \\ Mahuraja Purba ${ }^{4}$, Efvi Noyita \\ 1,2, 4, 5 Prodi PAK, STT REAL Batam \\ Prodi Teologi, STT Torsina, Surakarta \\ ritaevi@sttrealbatam.ac.id
}

\begin{abstract}
The level of drug abuse has worried all parties because it can damage the body and soul Social relations and the nation's future. Even so, there are still many who have not paid attention to this problem, perhaps they do not understand the multidimensional problems caused by drugs ranging from the dangers of drug addiction, dropping out of school, the destruction of social relationships, household fractures to serious crimes that are included in criminal law. This community service explains the dangers caused by drug abuse. It is hoped that after this community service, the GPI Batu Aji Center youth will also provide an explanation to their friends or their environment about the dangers of drugs so that all healthy and prosperous families are protected from the dangers of this illegal drug.
\end{abstract}

Keywords: Counseling, Anticipating, Drug Abuse, Youth, Indonesian Pentecostal Church

\begin{abstract}
Abstrak
Tingkat penyalahgunaan narkoba telah meresahkan Semua pihak Karena dapat merusak jiwa raga Hubungan sosial dan masa depan bangsa. Sekalipun demikian masih banyak yang belum perhatian terhadap masalah ini mungkin belum memahami masalah multidimensi yang ditimbulkan oleh narkoba mulai dari bahaya ketagihan obat, putus sekolah, hancurnya hubungan social, keretakan rumah tangga hingga kejahatan berat yang masuk dalam hukum pidana. Pengabdian masyarakat ini menjelaskan tentang bahaya yang diakibatkan penyalahgunaan narkoba. Diharapannya setelah pengabdian masyarakat ini remaja GPI Batu Aji Centre turut memberikan penjelasan kepada teman atau lingkungannya akan bahaya narkoba sehingga semua keluarga sehat, sejahtera terhindar dari bahaya obat terlarang ini. Kata kunci: Penyuluhan, Mengantisipasi, Penyalahgunaan Narkoba, remaja, Gereja Pentakosta Indonesia
\end{abstract}

\section{PENDAHULUAN}

Kecangihan teknologi dapat menimbulkan positif maupun dampak negatif. Keterbukaan informasi membuat remaja rentan oleh pergaulan bebas dan narkoba, jika dibiarkan akan banyak hal negatif yang dapat muncul. Batam yang merupakan perbatasan antara negara Singapura dan Malaysia menjadi pintu masuk peredaran narkoba, bukan saja transit, peredaran narkoba juga menjadi tujuan perdagangan ke Batam. Selama tahun 2019 hasil tangkapan BNN Kepri dan Polda untuk kasus narkoba ada $150 \mathrm{~kg}$ sabu dan 50.000 butir ekstacy. Hal ini ini disampaikan kepala BNNP Kepri Richard Nainggolan ${ }^{1}$ Januari 2020 pengguna narkoba di Kepri capai 26.000 orang $^{2}$ Hal tersebut membuat banyak orang tua merasa resah dan khawatir atas perkembangan anaknya. Remaja pada dasarnya tahu bahwa sebenarnya narkoba itu berbahaya bagi mereka, namun ada yang menggunakannya dengan alasan coba-coba dan ikut pergaulan. Faktor kegiatan sehari-hari remaja sering tidak terkontrol baik oleh pihak keluarga, sekolah, maupun masyarakat dan arus modernisasi yang telah menglobal ${ }^{3}$

Manfaat kegiatan pengabdian masyarakat memberikan kontribusi positif bagi pengetahuan remaja GPI Kavling Baru tentang bahaya penyalahgunaan narkoba. Penelitian sebelumnya terkait bahaya Narkoba, penelitian Pradana dkk menyatakan Penyalahgunaan narkoba berdampak buruk

\footnotetext{
${ }^{1}$ Bedianto, "Batam Menjadi Kota Tujuan Peredaran Narkoba $\square$ ” (Batam, 2019), accessed December 2 2019, https://rri.co.id/daerah/753081/batam-menjadi-kota-tujuan-peredaran-narkoba.

${ }^{2}$ Kepala Bnnp et al., "BNN Sebut Pengguna Narkoba Di Kepri Capai 26.000 Orang," last modified 2020, https://www.antaranews.com/berita/1239396/bnn-sebut-pengguna-narkoba-di-kepri-capai-26000-orang.

${ }^{3}$ Cut Rahmawati Lensoni, Meri Lidiawati, Noeroel Arham, Erna Savitri, "Sosialisasi Dampak Gadget, Bahaya Penyalahgunaan Narkoba Dan Pergaulan Bebas" 2, no. 1 (2019): 244-259, http://ejournal.bsi.ac.id/ejurnal/index.php/abdimas.
} 
REALCOSTER: REAL COMMUNITY SERVICE CENTER JOURNAL

Volume 3, No. 1, Maret 2020 (12-16)

hingga menimbulkan kematian. Kalangan yang rentan adalah generasi milenial. Informasi yang 
terbuka melalui media massa, internet terkait penyalahgunaan narkoba yang dilakukan publik figur sedikit banyak dapat mempengaruhi perilaku remaja yang menyaksikannya. Karena itu, perlu adanya edukasi pada generasi milenial tentang bahaya narkoba ${ }^{4}$

Tahapan Kegiatan

\begin{tabular}{|l|l|l|}
\hline No & Jadwal & Uraian Kegiatan \\
\hline & Sesi 1 & Ibadah \\
& Pukul $15.30-16.00$ wib & \\
\hline & Sesi 2 & Penyuluhan Jenis dan bahaya Narkoba \\
& Pukul $16.00-17.00$ wib & \\
\hline & Sesi 3 & Sesi Tanya Jawab \\
& $17-00-18.00$ wib & Doa Penutup \\
\hline
\end{tabular}

\section{Metode Penelitian}

Kegiatan ini menggunakan metode ceramah dan diskusi pendekatan yang dilakukan dengan sosialisasi. kegiatan dilakukan dimulai dengan ceramah memberikan informasi hal penting terkait narkoba dan dampak Penyalahgunaan narkoba serta cara menanggulanginya. Kemudian memberi solusi kepada remaja tentang permasalahan yang dihadapi melalui tanya jawab, kemudian menyusun tindakan lanjut berdasarkan hasil diskusi. Sebelum kegiatan pengabdian amsyarakat dilakukan di gereja, terlebih dahulu dialkukan kordinasi dengan Pembina remaja dan pimpinan gereja untuk dapat melaksanakan kegiatan ini dan sudah melakukan survey pada anak remaja yang rata-rata usia 13-18 tahun masih belum paham tentang bahaya dan pengaruh narkoba, namun sudah pernah mendengar narkoba. Para remaja dan pemuda menyambut baik kegiatan ini karena mereka menjadi lebih memahami tentang narkoba. pemuda ingin ke depan menggelar kegiatan kegiatan yang bersifat positif di gereja seperti olahraga, pentas seni, tata boga, pemuridan, pelatihan IT dan lain-lain. Penyuluhan ini diadakan selama satu hari yaitu pada tanggal 31 Januari 2020.

\section{HASIL DAN PEMBAHASAN Narkoba}

Undang-undang Nomor 22 pasal 1 tahun 1997 mendefinisikan narkoba sebagai zat atau obat yang berasal dari tanaman buatan atau semi buatan dan dapat menyebabkan penurunan kesadaran mengurangi sampai menimbulkan nyeri dan dapat mengakibatkan ketergantungan.

Dsebut juga dengan istilah Napza singkatan narkotika. Psikotropika dan zat adiktif

Narkotika atau dalam bahasa Inggris narcotics yang berarti obat bius merupakan bahan obat yang mempunyai efek kerja umumnya bersifat

1. Membius (menurunkan tingkat kesadaran seseorang)

2. merangsang (semangat aktivitas disebut juga dopping

3. ketagihan untuk terus menggunakannya

4. menimbulkan halusinasi

Jika jenis-jenis obat narkotika disalahgunakan untuk tujuan di luar pengobatan akan mengubah kerja saraf otak, sehingga berpikir berperasaan dan berperilaku tidak normal kecanduan dari zat adiktif menyebabkan pemakainya sulit dikontrol. ketagihan akan sampai pada tingkat yang parah yakni ketergantungan.

Berdasarkan risiko ketergantungannya, jenis narkoba dibagi menjadi 3 golongan antara lain

1. narkotika golongan 1 seperti ganja opium dan tanaman koka sangat berbahaya jika dikonsumsi karena menimbulkan efek kecanduan.

2. narkotika golongan 2 golongan 2 bisa dimanfaatkan untuk pengobatan dengan resep dokter, atau digunakan juga untuk tujuan pengembangan ilmu pengetahuan, diantaranya morfin, alfaprodina, golongan 2 juga berpotensi menimbulkan ketergantungan.

\footnotetext{
${ }^{4}$ https://jurnal.umj.ac.id/index.php/semnaskat/article/view/5397
} 
3. golongan 3 yang risiko ketergantungan yang cukup ringan yang digunakan dalam terapi atau tujuan pengembangan ilmu pengetahuan serta memiliki potensi ringan yang mengakibatkan ketergantungan contoh codein ${ }^{5}$

\section{Bahaya Penyalahgunaan Narkoba}

Pada tahap awal, efeknya mungkin dirasakan sebagai kenikmatan akan tetapi pada jangka panjang akan sangat berbahaya karena dapat menimbulkan ketergantungan. Beberapa ciri dari gejala ketergantungan para pemakai narkoba:

1. Ketergantungan secara fisik yaitu apabila tidak mendapatkan narkoba maka sifat candu akan merasa akan rasa sakit yang luar biasa pada tubuhnya disebut sakau. pengguna selalu ingin menambah takaran pemakaian kali pun tubuhnya sudah lemah ${ }^{6}$

2. Ketergantungan psikologis yaitu apabila tidak memperoleh narkoba akan menimbulkan gangguan jiwa berupa rasa gelisah, depresi, bingung dan gejala penyimpangan mental lainnya. pecandu selalu ingin mendapatkan narkoba dan tidak dapat menahannya sehingga menempuh cara apapun untuk mendapatkannya

\section{Bahaya Narkoba Untuk Jasmani}

Dampak awal penggunaan narkoba adalah kerusakan fisik. pengguna akan mengalami gangguan berat dan penyakit menular

1. Ketagihan dan ketergantungan

mereka yang mengkonsumsi narkoba akan menimbulkan kecanduan dimana seseorang akan selalu menambah dosis obat untuk mendapatkan ketenangan, jika tidak terpenuhi maka akan merasakan sakit pada sekujur tubuhnya titik gejala yang nampak adalah kekacauan pada saat berbicara lebih lambat penglihatan kabur pada malam hari serta mengalami kerusakan ginjal dan liver

2. badan rusak akibat terkena campuran zat lain

Narkoba sering dicampur dengan bahan bahan berbahaya karena sering dibuat ilegal bahan-bahan campuran ini beracun karena kadarnya cukup besar. sehingga pemakai terkena overdosis dan terkena campuran zat lain dalam kondisi biasa sa pemakai narkoba akan mengkonsumsi 3 atau lebih jenis narkoba sekaligus sehingga menyebabkan kerusakan bagian tubuh semakin parah $^{7}$

3. Gejala akibat kerja racun (intoksikasi)

awalnya narkoba adalah sebagai obat penyembuh terhadap penyakit jika dilakukan dengan benar dan dibawah pengawasan dokter. namun jika disalahgunakan kan makan narkoba dapat menjadi racun membahayakan yang sedikit demi sedikit Akhirnya akan menumpuk dan dan berkembang merusak gangguan fungsi organ tubuh

4. Bertindak di bawah pengaruh narkoba dengan tingkat kelas ringan biasanya langkahnya sempoyongan, pandangannya kurang jelas emosi meningkat cenderung tidak punya rasa malu fungsi otak benar-benar tidak berfungsi dengan baik. pada level Jenis narkoba yang lebih ganas dampaknya mengakibatkan kondisi saraf otak pemakai narkoba telah terganggu dengan berbuat di bawah pengaruh obat, Keterampilan- keterampilan motorik, koordinasi sama penglihatan Kecepatan juga telah menjadi kacau. Pemakai narkoba di perkotaan lebih banyak di pedesaan, Maka sangat berbahaya bila pemakai narkoba mengendarai kendaraan bermotor karena konsentrasi serta koordinasi akan kacau

\section{Bahaya Narkoba Terhadap Mental}

Narkoba merusak kerja otak sehingga mengganggu dan mengakibatkan kesulitan belajar juga memicu perubahan psikologis seperti gembira berlebihan apatis, dsphoria gangguan fungsi social.

\footnotetext{
${ }^{5}$ Oktaviana Purnamasari Dimas Adhie Pradana, Dinda Amelia, Fira Shavera, "SOSIALISASI JENIS DAN BAHAYA NARKOBA BAGI KESEHATAN PADA IKATAN PEMUDA WARU RW 05 PAMULANG BARAT, TANGERANG SELATAN," in Prosiding Seminar Nasional Pengabdian Masyarakat LPPM UMJ, 2019, https://jurnal.umj.ac.id/index.php/semnaskat/article/view/5397.

${ }^{6}$ Ibid.
} 
Narkoba memperlabil psikologi dan mempengaruhi perilaku. Orang yang terkena pengaruh narkoba kondisi psikologi nya akan menjadi labil dan mudah dipengaruhi orang lain, semangat cepat hilang ${ }^{8}$. Hal ini disebabkan karena kondisi saraf otak telah terganggu dan bertindak di bawah pengaruh obat akibatnya hilang kontrol akal sehat. Manusia dapat berkreasi karena akal terjaga sehat sehingga dapat berpikir cerdas untuk kemakmuran hidupnya namun sebaliknya, jika akal pikirannya kacau akibat mengkonsumsi narkoba maka perilaku merusak menganiaya dan meresahkan masyarakat, Mereka memiliki hati namun tidak merasa memiliki akal namun lemah berpikir, Alkitab menyebutnya kaum pemberontak (yeh. 12:2). Oleh karena itu agama Kristen maupun agama lain mengajarkan kepada umatnya untuk menjauhi mabuk-mabukan serta minum minum yang memabukkan. Disamping itu pelaku narkoba akan berdampak pada daya pikir yang terus menurun akibatnya tidak akan mampu menyelesaikan masalah dan pekerjaan dengan baik. pemerintah telah berusaha menyediakan rumah rehabilitasi untuk menampung orang-orang yang yang terkena pengaruh narkoba.

\section{Menyikapi Penyalahguna Narkoba}

Adapun cara menyikapi penyalahgunaan narkoba9

Saat ini banyak pusat-pusat rehabilitasi baik yang difasilitasi oleh pemerintah maupun swasta. Ada dengan perkembangan informasi maka tidak sulit untuk menemukan Lembaga-lembaga rehabilitasi narkoba. Pusat rehabilitasi bukan penjara, tetapi merupakan Lembaga yang dirancang sedemikian rupa untuk meminimalisir dan menghentikan kecanduan narkoba dengan berbagai terapi yang diperlukan.

Pencadu narkoba juga adalah manusia biasa yang membutuhkan support supaya dapat terlepas dari belenggu narkoba $\mathrm{k}$ dan Tuhan menolong. Pecandu narkoba memerlukan dukungan moril dari orang tua atau keluarga yang akan sangat berarti bagi mereka.
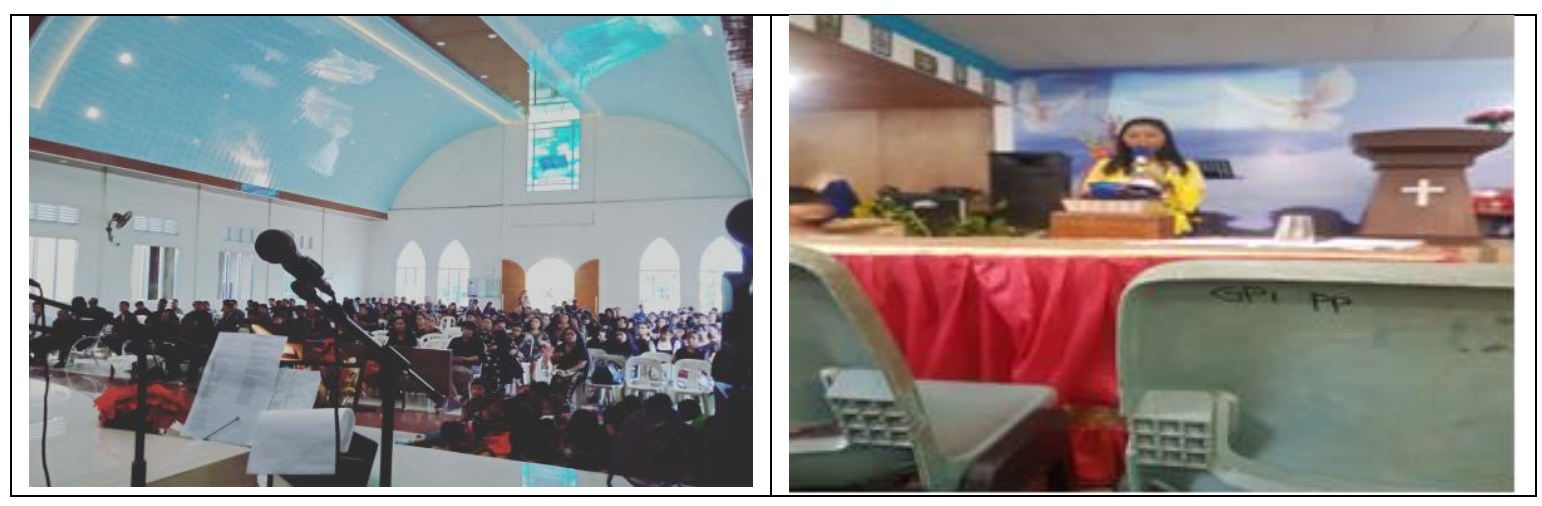

Gambar 1. Suasana Penyuluhan Penyalahgunaan Narkoba pada Remaja GPI Batu Aji Centre

\section{SIMPULAN}

Penyalahgunaan narkoba berdampak buruk bagi generasi milenial, oleh karena itu perlu dilakukan edukasi secara luas guna memberikan informasi seluas-luasnya mengenai bahaya penyalahgunaan narkoba. sosialisasi yang berupa penyuluhan anti narkoba dilakukan untuk menyampaikan jenis jenis dan bahaya narkoba yang harus dihindari. disamping penyuluhan sesi tanya jawab diberikan Sehingga peserta mendapat wawasan yang lebih luas dan dan dapat diketahui permasalahan permasalahan yang dihadapi remaja di setiap hari pada lingkungannya baik kepada sesama teman maupun masyarakat. dengan pendekatan persuasif ini dapat mempengaruhi perilaku remaja agar menghindari penggunaan narkoba respon remaja positif dan dan mengakui mendapatkan

\footnotetext{
${ }^{8}$ Abdul Majid, Bahaya Penyalahgunaan Narkoba (Semarang: Alprin, 2019). Hal 36

${ }^{9}$ Weni Rahayu, Mengantisipasi Penyalahgunaan Narkoba (Klaten, Jateng: Mediantara Semesta, 2009).
} 
wawasan baru dan berharga tentang bahaya penyalahgunaan narkoba sehingga mereka dapat melakukan pencegahan lebih dini agar terhindar dari bahaya penyalahgunaan narkoba.

\section{DAFTAR PUSTAKA}

Ardilla, Fauziya, and Ike Herdiana. "Penerimaan Diri Pada Narapidana Wanita." Jurnal psikologi Kepribadian dan Sosial 2, no. 1 (2013): 1-7.

Gussak, David. "The Effects of Art Therapy on Male and Female Inmates: Advancing the Research Base." The Arts in Psychotherapy 36, no. 1 (February 2009): 5-12. https://linkinghub.elsevier.com/retrieve/pii/S0197455608000841.

Halidin, Ali. "Identitas Gender Dalam Perspektif Agama Kristen.” Al-MAIYYAH : Media Transformasi Gender dalam Paradigma Sosial Keagamaan 10, no. 1 (2017): 25-44.

Kusumaningsih, Luh Putu Shanti. "Penerimaan Diri Dan Kecemasan Terhadap Status Narapidana." Jurnal Psikologi Ilmiah 9, no. 3 (2017): 234-242.

Latif, Helen Farida. "Pengaruh Pengajaran Dan Persekutuan Terhadap Tingkat Pertumbuhan Rohani Anak Dan Remaja." EPIGRAPHE: Jurnal Teologi dan Pelayanan Kristiani 1, no. 1 (2017): 119138.

Simanjuntak, Fredy. "Mission Driven Prayer.” In KIngdom Economy and Mission, 105-112, 2018. https://doi.org/10.31219/osf.io/znef2.

Sunaryo, Thomas. "Perpustakaan Penjara." Majalah Bahana. Jakarta, 1983.

Supratiknya, A. Merancang Program Dan Modul Psikoedukasi. Yogyakarta: Universitas Sanata Dharma. Yogyakarta: Universitas Sanata Dharma, 2011.

https://repository.usd.ac.id/12880/1/2011 Merancang Program dan Modul Psikoedukasi Edisi Revisi.pdf. 